\title{
Effect of solid-solution temperature on microstructure of incoloy 825 alloy and its corrosion behavior in a polluted marine environment
}

\author{
Min Zhu*, Zhongping Le, Yongfeng Yuan, Shaoyi Guo, Jian Zhou
}

School of Mechanical Engineering \& Automation, Zhejiang Sci-Tech University, Hangzhou 310018, PR China

"E-mail: zmii666@126.com

doi: $10.20964 / 2020.02 .53$

Received: 3 October 2019 / Accepted: 30 November 2019 / Published: 31 December 2019

Effects of solid-solution temperature on microstructure and its corrosion behavior of incoloy 825 alloy in a polluted marine environment were investigated by electrochemical tests and periodic wet-dry cycle test. The corrosion resistance of alloy sample improves with the rise of solid-solution temperature. The corrosion law of the alloy is closely related with different microstructures. The increase in grain size and the amount of $\operatorname{Ti}(\mathrm{C}, \mathrm{N})$ precipitates can decrease the corrosion degree. The electrochemical parameters of $R_{f}, R_{c t}$ and $i_{p}$ indicate that the passive films formed on the samples with different microstructures have different protective property. All samples mainly exhibit the feather of localized corrosion, and the degree of localized corrosion significantly reduces with an increase in the solid-solution temperature.

Keywords: Solid-solution temperature; Corrosion behavior; Microstructure; Localized corrosion

\section{FULL TEXT}

(C) 2020 The Authors. Published by ESG (www.electrochemsci.org). This article is an open access article distributed under the terms and conditions of the Creative Commons Attribution license (http://creativecommons.org/licenses/by/4.0/). 